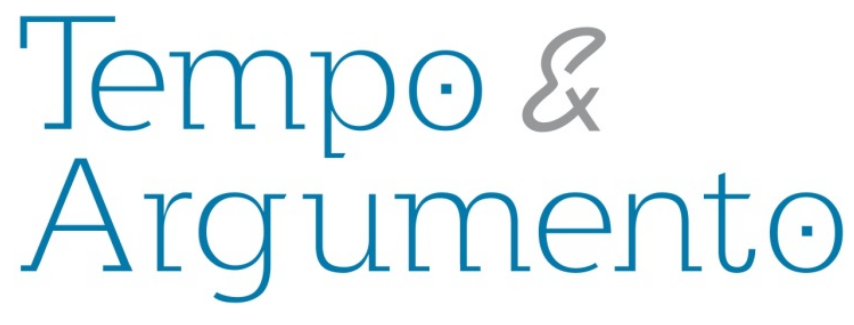

\title{
Entre o porto e a história: revitalização urbana e novas historicidades no porto do Rio de Janeiro com vistas às Olimpíadas de 2016
}

\begin{abstract}
Resumo
A partir da análise das ações, relatos e documentos elaborados por agentes do governo municipal relativos ao projeto o Porto Maravilha, propõe-se discutir as características e os processos urbanos atuantes sobre a zona portuária, considerando as relações entre a espacialidade e a historicidade da região. $\mathrm{O}$ artigo parte de uma discussão histórica que busca pensar no tempo a relação entre o porto e a cidade. Em sequência, investe em uma análise sociológica sobre o atual projeto Porto Maravilha, suas pretensões de criar uma ruptura na história da urbe, através da articulação de um discurso que vincula a decadência portuária com a necessidade de regeneração do porto para se conquistar uma reformulação da cidade como um todo. Essa pretensão de estabelecer um marco de ruptura por parte da prefeitura do Rio de Janeiro também esconde as continuidades que esse projeto estabelece com outros projetos pensados para a cidade. $\mathrm{O}$ artigo discute também a maneira como o referido plano de reformulação do porto busca se estabelecer a despeito da historicidade e da espacialidade da região.
\end{abstract}

Palavras-chave: Portos - Rio de Janeiro; Urbanização Rio de Janeiro; Rio de Janeiro (RJ) - Prefeitura.

\author{
André Nunes Azevedo \\ Doutorado em História Social da Cultura pela \\ Pontifícia Universidade Católica do Rio de \\ Janeiro (PUC-RJ). Professor do Programa de \\ Pós-graduação em História na Universidade do \\ Estado do Rio de Janeiro (UERJ). \\ Brasil \\ azevedoemigrante@gmail.com
}

\section{Leopoldo Guilherme Pio}

Doutorado em Ciências Sociais pela Universidade do Estado do Rio de Janeiro (UERJ). Pesquisador do Laboratório de Antropologia do Espaço e Lugares (LAARES IFCS I UFRJ). Brasil leoguipio@gmail.com

\section{Para citar este artigo:}

AZEVEDO, André Nunes; PIO, Leopoldo Guilherme. Entre o porto e a história: revitalização urbana e novas historicidades no porto do Rio de Janeiro com vistas às Olimpíadas de 2016. Revista Tempo e Argumento, Florianópolis, v. 8, n. 19, p. 185 - 208. set./dez. 2016.

\section{DOI: $10.5965 / 2175180308192016185$}

http://dx.doi.org/10.5965/2175180308192016185 


\title{
Between the port and history: urban revitalization and new historicities at the port of Rio de Janeiro with a view to the 2016 Olympics Games
}

\begin{abstract}
Based on the analysis of reports, documents and actions planned by the municipal government related to the Porto Maravilha project, we discuss the characteristics and urban processes of the port area, considering the relationship between spatiality and the historicity of the region. The article starts with a historical discussion about the relationship between the port and the city and in sequence, invests in a sociological analysis of the current project, its pretensions to create a break in the history of the metropolis, through the articulation of a discourse that links the port decay with the need for regeneration of the port to gain a reformulation of city as a whole. This pretension to establish a landmark break from the municipality of Rio de Janeiro also hides the continuities that this project establishes with other projects thought to the city. The article also discusses how the plan referred to redesign the port seeks to establish despite the historicity and spatiality of the region.
\end{abstract}

Keywords: Ports - Rio de Janeiro; Urbanization - Rio de Janeiro; Rio de Janeiro (RJ) - City Hall.

\section{Introdução}

O projeto Porto Maravilha foi concebido pela Prefeitura do Rio de Janeiro para transformar o porto com vistas às Olimpíadas de 2016. Reflete em seus objetivos formas contemporâneas de pensar e intervir na cidade contemporânea, vinculados à abordagem estratégica da cidade e ao novo status do patrimônio na gestão urbana, entre outros 
fatores (PIO, 2014). Trata-se de um plano que pretende transformar e influenciar a cidade, sendo apresentado pela Prefeitura do Rio de Janeiro como uma proposta supostamente sem conexão com ideologias urbanas específicas ou um contexto histórico singular. Essa pretensão de estabelecer um marco de ruptura por parte da prefeitura do Rio de Janeiro também esconde as continuidades que esse projeto estabelece com outros projetos pensados para a cidade.

O projeto responde a necessidades econômicas e culturais contemporâneas. Por outro lado, seu perfil remete também a uma serie de processos históricos que constituíram a espacialidade do porto. Entendemos que os processos de revitalização, preservação e patrimonialização de áreas "degradadas" como a Zona Portuária correspondem à reconfiguração das relações entre passado, presente e futuro, isto é, à constituição de um novo regime de temporalidade. Neste artigo propõe-se discutir especificamente a relação entre a espacialidade e a historicidade da região. Assim, devese perguntar: como se estabelece a relação entre porto e cidade? De que maneira as intervenções sobre a região modificaram sua espacialidade e historicidade? Que relação se estabelece entre tradição e modernidade na cidade do Rio de Janeiro? Ou, em outros termos, que conexões se estabelecem entre demandas econômicas e culturais do mundo contemporâneo e as identidades culturais e históricas locais?

Para abordar tais questões, o texto se divide em três seções. Em primeiro lugar, discutimos as origens históricas da zona portuária, considerando o momento em que “cidade-porto" se fazia importante referência para os processos de desenvolvimento econômico local e nacional. Em sequência, investimos em uma análise sociológica sobre o atual projeto Porto Maravilha, enfatizando suas pretensões de criar uma ruptura na história da urbe, através da articulação de um discurso que vincula a decadência portuária com a necessidade de regeneração do porto. Por fim, apresentamos uma análise crítica dos discursos e interesses que sustentam a imagem atual da zona portuária, discutindo a maneira pela qual o referido plano de reformulação do porto se legitima. 


\section{Aspectos Históricos do Porto}

A história da cidade do Rio de Janeiro é fortemente vinculada ao seu porto. No período colonial carioca esse espaço cumpriu um papel fundamental no desenvolvimento da cidade. Um dos fatores decisivos para a escolha portuguesa de estabelecer um povoamento que foi o núcleo inicial foi a presença do porto. No século XVI o Rio de Janeiro se encontrava localizado nas zonas mais ao sul das possessões portuguesas estabelecidas no continente americano pelo Tratado de Tordesilhas. Assim, poderia ser um importante porto de aguada no itinerário que Portugal buscava estabelecer em direção ao ponto estratégico de maior riqueza da América do Sul então: a prata do Potosí, no atual território boliviano, que era escoada em contrabando para a embocadura do Rio da Prata (CANABRAVA, 1984). A função portuária da cidade, desde o seu período inicial, nos meados do século XVI, também justificou a existência da cidade por outras razões, pois, se foi um importante porto de reabastecimento na longa viagem de Portugal rumo ao estuário do Rio da Prata, também o foi para as diversas embarcações portuguesas que atravessavam o Atlântico Sul vindas da Europa rumo às mais diversas possessões portuguesas, como a África Oriental, a Península Arábica, a Península Indiana, a China e o Sudeste da Ásia. Da mesma maneira, o porto do Rio de Janeiro no século XVI também foi importante como centro de distribuição de alimentos para as cidades de agricultura mercantil escravista do Nordeste (FRAGOSO; FLORENTINO, 1993, p. 33), então mais prósperas. Ao longo de todo o período colonial, e até boa parte do século XIX, o porto cumpriu um papel decisivo para o Rio de Janeiro, alimentando o que foi o principal elemento de sua economia, o tráfico de escravos com o litoral africano, sobretudo Angola (BOXER, 2010). No século XVIII, em 1763, a cidade se torna sede do Vice-Reino por ter sido o seu porto eleito como lugar de emissão das remessas oficiais de minérios preciosos saídos da região de Minas Gerais (RODRIGUES, 2002). Em 1808, já ocupando um lugar destacado no interior do Império português, é a cidade que recebe a Corte Real do Príncipe Regente D. João, futuro D. João VI, que tem como a sua principal ação política para a América Portuguesa a abertura dos portos à Grã-Bretanha, o que realçou o já pronunciado destaque que o porto carioca sustentava no âmbito das possessões lusitanas na América. Com a emancipação política em 1822 e o crescimento da cultura 
cafeeira no Vale do Paraíba Fluminense desde 1830, o porto reforça a imbricação existente, desde o período colonial, entre o seu crescimento e o crescimento da cidade. Nesse período o porto da então Corte Imperial se sedimentou como um dos maiores portos da América do Sul, somente encontrando rival à altura no seu congênere de Buenos Aires.

Com o advento da República e a decadência da cultura cafeeira no Vale do Paraíba Fluminense em fins do século XIX, o porto do Rio de Janeiro mantém a sua liderança econômica no cenário nacional, mas já é ultrapassado no quesito volume de exportações pelo porto de Santos em 1894, então embalado pelo desenvolvimento crescente da cafeicultura no interior paulista (LAMARÃO, 1991, p. 141). No entanto, longe de perder o seu vigor, o porto da Capital Federal vê redimensionada a sua função de centro exportador, sua principal característica no Brasil monárquico. Com a República veio o fenômeno do Encilhamento e o crescimento exponencial da população da cidade ${ }^{1}$, bem como do espírito arrivista e do cosmopolitismo agressivo no Rio de Janeiro (SEVCENKO, 2003, p. 36-57). Essas transformações na cidade, ocorridas na esteira da abolição da escravidão em 1888 e da instauração do novo regime em 1889, verteram o vetor de crescimento do porto carioca para a atividade importadora. Essa reconfiguração do seu padrão de comércio externo verificou-se decisiva para uma das decisões governamentais mais marcantes da história do porto, que teria impacto em toda a estrutura urbana de seu entorno durante o século XX, a decisão do Presidente Rodrigues Alves de reformá-lo anunciada no seu discurso de posse, em 15 de novembro de 1902.

A decisão de Rodrigues Alves de operar a maior reforma portuária do Brasil até então deveu-se justamente à mudança no padrão de comércio externo que mencionamos, agora centrado nos negócios de importação. Isso porque a constituição republicana de 1891 passou a atribuir o recolhimento dos impostos sobre as exportações aos estados, ao passo que destinava os tributos das importações ao Governo Federal. Isso se deu em um contexto de progressivo aumento das arrecadações federais pelos

\footnotetext{
${ }^{1}$ Cabe lembrar que, segundo as estatísticas oficiais do governo brasileiro, em 1872 o Rio de Janeiro apresentava uma população de 274.972 habitantes, progredindo para 522.651 moradores em 1890 , e saltando a 811.443 viventes em 1900. Ver: http://www.cens02010.ibge.gov.br/sinopse/index.php? dados $=6 \&$ uf $=00$
} 
porto carioca nessa dimensão da economia brasileira, estratégica para o equilíbrio das contas federais, fazia-se altamente relevante reformar o porto e seu entorno para o escoamento de mercadorias pela cidade, a fim de aumentar a sua capacidade de captação de comércio e, consequentemente, aumentar a arrecadação federal e a balança de pagamentos do governo brasileiro.

A reforma urbana do porto, promovida pelo Governo Federal, sob a responsabilidade política do Ministério da Viação, Transportes e Obras Públicas, gerido então pelo engenheiro militar Lauro Müller, e dirigida em sua dimensão técnica pelo engenheiro, membro do Clube de Engenharia, Francisco Bicalho, buscou não somente ampliar a capacidade de receber mercadorias do porto com aterramentos, a ampliação do seu píer, armazéns e aumento do seu calado, como também, e sobretudo, pela reordenação da estrutura viária do seu entorno, na chamada região portuária, que abriga os bairros da Saúde, Gamboa e Santo Cristo. Essa ação urbanística governamental, conduzida por uma lógica de engenharia logística centrada na distribuição de mercadorias pelo centro da cidade, desconsiderou qualquer sentido urbanístico de integração da população local àquele espaço. A reforma urbana conduzida pelo engenheiro Francisco Bicalho não pensou o novo espaço portuário que projetara como um lugar de usufruto da população local, mas sim como um espaço para trânsito e escoamento ao centro da cidade das mercadorias chegadas em volume cada vez maior no porto reformado. Conforme podemos verificar na comparação das plantas do porto carioca antes e depois da reforma urbana de Rodrigues Alves, o que foi realizado no espaço portuário da cidade foi um conjunto de ruas alargadas que estabeleciam uma relação de paralelismo e perpendicularidade, realizadora de ângulos de 90 graus, que buscavam estabelecer ligações rápidas e eficientes de parte a parte, sem maiores preocupações para além desse objetivo (AZEVEDO, 2003, p.38).

Não obstante, em que tenha pesado nessa reconfiguração do espaço do porto o sentido meramente pragmático de dar resolução ao problema da distribuição de 
mercadorias ao Centro, a região portuária seguiu sendo uma região com significativa presença habitacional, sobretudo de populações de negros que ali labutavam desde o período imperial, principalmente na estiva e em pequenas oficinas, mas também da população de imigrantes europeus meridionais, a maioria composta de portugueses, que atuavam no pequeno comércio da região, em diversos ofícios da Estrada de Ferro Central do Brasil, em transportes na área portuária, e também na estiva (CARVALHO, 1995, p. 91; LAMARÃO, 1991, p. 103). Assim, mesmo tendo recebido uma reforma viária que apenas pensou o seu espaço como um espaço de função, e não de uso ${ }^{2}$, podemos notar que a região portuária nunca foi desconectada da cidade, sendo, de maneira distinta, integrada a ela das mais diversas formas, seja pela proximidade com a Estada de Ferro Central do Brasil, com o metrô e a rodoviária ou mesmo com o restante do Centro do Rio de Janeiro.

Algo que também deve ser considerado quanto a atual zona portuária é que, não obstante a baixa presença de viandantes em alguns dos seus trechos, como no caso paradigmático da Avenida Rodrigues Alves ${ }^{3}$, a maior parte da sua área - bairros da Saúde, Gamboa e Santo Cristo - perfaz uma região com considerável presença habitacional, bem como de comércio e serviços. Essa população local, em muitos casos, está lá estabelecida há algumas gerações, vem vivenciando o cotidiano dessa região, com uma vida social vigorosa em seu espaço que, no mais, devemos registrar, não foi historicamente mais abandonado do que diversas áreas da urbe carioca. A maioria dos bairros e regiões do Rio de Janeiro sofreram com o desmazelo do poder público no transcorrer do século XX. Assim, longe de tratar-se de um espaço vazio da cidade, ou notadamente mais decadente que os demais bairros da urbe, como muitas vezes parece nos indicar o discurso oficial emanado do poder municipal, - que abordaremos mais adiante, - trata-se de uma área rica em historicidade, em presença humana que vem constituindo o seu espaço com as suas vivências ao longo do tempo na região.

\footnotetext{
${ }^{2}$ Referimo-nos aqui à dialética de transformação espacial relativa à relação de uso e função do espaço urbano estabelecida pela estudiosa do fenômeno urbano Lucrécia Ferrara. Sobre a dinâmica dessa relação, ver: FERRARA, Lucrécia D’Aléssio. Ver a cidade. São Paulo: Nobel, 1982.

${ }^{3} \mathrm{~A}$ atual Avenida Rodrigues Alves corresponde à antiga Avenida do Cais, que margeava o porto no início do século XX.
} 
O fenômeno cidade não pode ser visto como uma coisa, um dado simplesmente, mas sim como uma relação que os seus habitantes estabelecem com o seu espaço, que na geografia são traduzidos pelos conceitos de espacialidade, geograficidade, ou mesmo de topofilia, que são conceitos relativos às formas de uso do espaço, bem como os elos de afeição que unem as pessoas aos lugares (HOLZER, 2003; TUAN, 1980) ${ }^{4}$. Como diz Richard Sennet (1994), a cidade não é só pedra, mas também é carne, ou seja, ela é feita fundamentalmente da experiência que nela é depositada historicamente, e consolidada em forma de cultura urbana. A cidade é, portanto, fundamentalmente, uma experiência coletiva no espaço, uma espacialidade, como assim o são as suas regiões e bairros. Assim, a região portuária não é, de forma alguma, desprovida de espacialidade, nem tampouco de historicidade ${ }^{5}$, mas sim um espaço que preexiste a qualquer projeto público de intervenção, que não está vazio, nem é mais degradado que o conjunto da urbe, mais carente de intervenção, portanto.

Da mesma forma, o Rio de Janeiro não depende da reformulação urbanística da região portuária para o resgate da cidade como um todo, ou, como muito propalado, de sua reordenação material ou simbólica para o resgate de sua capitalidade. Se a cidade não é coisa, mas sim uma relação com o espaço e uma experiência no tempo, ou seja, se se constitui através de sua espacialidade e de sua historicidade, logo qualquer projeto que almeje redimensionar a urbe não pode constituir-se de forma metonímica, tornando uma parte a fiadora do todo, nem pode, outrossim, pensar a cidade como mero objeto passivo, tabula rasa sem qualquer historicidade e espacialidade, de qualquer pretensa intervenção técnica regeneradora.

\footnotetext{
${ }^{4}$ Não é o objetivo deste artigo discutir esses conceitos da geografia. Não obstante, remetemos o leitor à rica discussão desses conceitos realizada por Holzer, que traz forte influência dos estudos de Y Fu Tuan. Esse último geógrafo é indispensável para se pensar a relação entre afetividade e lugar. De todos esses conceitos o que mais oferece elementos para aprofundar a vinculação afetiva que o cidadão estabelece com dado espaço da urbe, a relação entre sentimentos e as experiências espaciais, e mesmo a relação entre cultura e meio ambiente, é o de topofilia.

${ }^{5}$ Trabalhamos o conceito de historicidade como sendo a experiência coletiva de um povo no tempo. Gadamer fala da historicidade como algo que compõe a constituição íntima do espírito de um povo. Entendemos o conceito de espacialidade como a experiência humana no espaço, produtora de uma cultura relacionada aos usos desses espaços. Sobre esse conceito em Gadamer, ver: GADAMER, Hans G. FROUCHON, Pierre (Org.). O problema da consciência histórica. Rio de Janeiro: Ed FGV, 1998. p. 39-46. Sobre o conceito de espacialidade, ver: HOLZER, Werther. Op. cit. p. 113-123.
} 
Não obstante, o projeto do Porto Maravilha, conduzido pela Prefeitura Municipal do Rio de Janeiro, na expectativa de sua legitimação enquanto ação de intervenção urbanística do poder público sobre uma área da cidade, buscou constituir um conjunto de referências que convocassem a sociedade carioca à convalidação de seu projeto sem, contudo, levar em conta as contradições e diversidades que a historicidade e a espacialidade da urbe forneceram àquele espaço do Rio de Janeiro.

\section{Concepções e princípios Porto Maravilha}

O Estudo de Impacto de Vizinhança, principal documento oficial a respeito do projeto Porto Maravilha, especifica que o programa de recuperação e reestruturação dos sistemas de infraestrutura urbana permitirá a valorização da região, o aumento de renda para o estado, a atração de investimentos para "novas unidades residenciais, comerciais e de serviços, sedes de empresas, estabelecimentos hoteleiros, equipamentos culturais e de lazer" e, por fim, a transformação da região da Zona Portuária numa "área dinâmica que seja uma nova referência de planejamento urbano para a cidade" (CDURP/IPP, 2010, p. 28). A Prefeitura pretende aumentar a população residente de cerca de 30 mil para 100 mil habitantes nos próximos dez anos. A expectativa é que a população flutuante atinja 800 mil. Vale notar que o retorno do uso habitacional da Área Central é uma questão levantada pelos técnicos envolvidos no Corredor Cultural, como Augusto Ivan Pinheiro e Nina Rabha, e que a lei que volta a permitir novas unidades residenciais no centro da cidade é de 1994 (Lei 2236/1994). Sem essa nova legislação, que revoga o Decreto-lei 322/1976, que proibia construções de uso residencial em todo o Centro, não seria possível desenvolver uma política de incorporação imobiliária atualmente.

Destacam-se nos relatos obtidos durante pesquisa a respeito do processo de revitalização e patrimonialização da região (PIO, 2014) dois argumentos principais, que visam legitimar o projeto: a ideia de que a área foi reconquistada através de processos simultâneos de modernização e preservação histórica e a constatação do resgate da relação natural entre a identidade da região e a identidade da cidade. O "reencontro" da área com a cidade pode ser entendido tanto no sentido geográfico - a ruptura de um 
suposto isolamento da região - quanto simbólico, no sentido de aproximar a identidade reinventada da região com a identidade da cidade. Propõe-se, nesse sentido, uma oposição entre o estado "degradado" da região e o presente de transformações. A renovação da região em termos urbanísticos e simbólicos através da "integração" com o resto da área central permitiria a própria modernização da cidade.

Ao mesmo tempo, a "retomada do crescimento" da cidade, destacada em diversos relatos e documentos analisados nos últimos anos, é identificada com os megaeventos esportivos que tem ocorrido na cidade e no país. Nesse processo, tenta-se resgatar a importância da cidade, enfatizando-se sua centralidade econômica em um “momento especial”, como a principal responsável pela economia de serviços e turismo no país. O arquiteto Sérgio Dias (Secretário Municipal de Urbanismo entre 2008 e 2013), em seu texto de apresentação do projeto no livro Porto Maravilha e o Rio de Janeiro + seis casos de sucesso, afirma:

A cidade tem nesse movimento [de reencontro com o porto] algo essencial para alinhar sua trajetória com a curva de crescimento do Brasil. Atualmente o país desponta como um dos líderes em crescimento global. Apesar de o Brasil dispor de enormes riquezas em termos de matériasprimas [...], é o setor de serviços o que mais contribui para o PIB. E o Rio de Janeiro tem uma participação essencial nesse contexto, especialmente no que se refere à oferta de serviços e de opções de turismo (DIAS, 2010, p. 213).

Esse discurso triunfante se caracteriza pela ideia de que o Rio de Janeiro vive um momento importante na sua história e se prepara para a organização de eventos, “embalando o encontro porto-cidade”. A revitalização da Zona Portuária é vista como processo essencial para alinhar a trajetória da cidade "com a curva de crescimento vivida pelo Brasil” (DIAS, 2010, p. 214). Entretanto, essa relação entre o centro da cidade (isto é, a área central de negócios e o centro histórico) e a região portuária é naturalizada, pois, ao analisarmos outros planos de modernização da cidade, podemos perceber que o vetor de crescimento varia conforme o contexto histórico e os interesses em questão. Podemos citar como exemplo o plano de reforma urbana do Presidente Rodrigues Alves, cujo sentido da intervenção foi deslocar o porto do Centro como lugar de usos da população carioca, conectando-o com essa região apenas como um lugar de evasão de 
Outra crítica possível diz respeito ao uso da noção de centro urbano. Caberia perguntar que tipo de "resgate" se propõe ao centro, para quem e com qual interesse. 0 resgate de uma pretensa "centralidade" da área (em termos históricos, econômicos ou culturais) é uma representação elaborada pelo poder público que não considera especificidades históricas da Zona Portuária, nem tampouco as concepções estigmatizantes que caracterizaram a região durante os séculos XIX e XX. Cabe ressaltar que o projeto do Porto Maravilha não leva em conta a tradição de usos do espaço portuário carioca. Antes, no discurso oficial do poder municipal, busca caracterizar essa região apenas como uma região decadente, sem levar em conta a historicidade e a espacialidade que ela apresenta. O que se passa é que as dimensões de experiência no tempo e no espaço dessa área da cidade são desconsideradas, pois o importante é a caracterização dessa zona como "decadente" e, nessa qualidade, um objeto legítimo da intervenção do poder público para revitalizá-la, “resgatá-la”, que é um termo sobremodo utilizado nos discursos da prefeitura do Rio de Janeiro, a fim de "resgatar" toda a cidade através da ação reformadora nessa região. Desta maneira, o porto passa a afigurar-se como metonímia da urbe, pois a "regeneração" da cidade derivaria da reforma do porto.

Segundo Rabah (2004), a área foi associada à escravidão, à pobreza, à habitação proletária, doenças contagiosas e ao "perigo e a má fama" em vários momentos de sua história. Essas características são pensadas de duas maneiras pelos discursos oficiais. Primeiramente, a atribuição de má fama é omitida ou amenizada para que não haja contradições evidentes entre o perfil histórico da região e o modo pelo qual essa é contemporaneamente representada. Em outros contextos, esses usos tradicionais são abordados e reduzidos a determinadas categorias acusatórias: decadência, abandono, degradação. Nesse segundo sentido, elabora-se uma oposição entre o passado recente da área e o perfil sociocultural e econômico que se está construindo no presente. Tratase, nesse sentido, de enfatizar a resolução de um conjunto de "problemas" que

\footnotetext{
${ }^{6}$ Cf. AZEVEDO, André N. de. Op. cit.
} 
A região portuária tem sido objeto de diversos planos de revitalização e valorização histórica desde os anos 80. Com a lei 971/1987, a região ganha status patrimonial, dando origem à área de proteção ambiental do SAGAS (região dos bairros Saúde, Gamboa e Santo Cristo) ${ }^{7}$. Com o Plano Diretor (1992), estabeleceram-se as bases para uma política pública voltada para a proteção do patrimônio cultural e se instituíram diferentes tipos de unidade de conservação, entre elas as Áreas de Proteção Ambiental APAs (área dotada de características ecológicas) - e as APACs (área que apresenta interesse cultural relevante). Em 1993, um diagnóstico socioeconômico foi elaborado para o estabelecimento da Área Especial de Interesse Urbanístico no sentido de definir características de ocupação na região do SAGAS. Em 2001, a Prefeitura da cidade definiu como prioridade para a Secretaria de Urbanismo um programa de revitalização da área portuária, desenvolvendo o "Porto do Rio - Plano de Recuperação e Revitalização da Região Portuária do Rio de Janeiro" (RIO DE JANEIRO, 2001).

Entretanto, diversos obstáculos legais e políticos impediram que esse último plano fosse efetivado. Tais obstáculos se devem não apenas às dificuldades de desapropriação de imóveis e de negociação entre os poderes municipal, estadual e federal, como também à ausência do marco legal apropriado e a uma série de divergências entre os atores envolvidos - a Prefeitura da cidade, que tem a competência de alterar os parâmetros urbanísticos vigentes, o governo do Estado e as instituições proprietárias de terras da região (especialmente a Companhia Docas do Rio de Janeiro e a Rede Ferroviária Federal). Segundo a leitura de Alberto Correa, secretário de Urbanismo entre 1994 e 1998:

\footnotetext{
${ }^{7} \mathrm{~A}$ lei prescrevia a submissão de todas as licenças de obras e os projetos de parcelamento à avaliação do Departamento Geral de Patrimônio Cultural (DGPC), da Secretaria Municipal de Cultura. A regulamentação das normas de uso do solo se deu por meio do Decreto $N^{\circ} 7.351$, de 14/01/88, que, entre outros dispositivos, limitou a altura das edificações e criou zonas de proteção ambiental nas quais identificou os imóveis que deveriam ser preservados, proibindo a descaracterização de suas fachadas e telhados. Instituiu também o Escritório Técnico do Projeto SAGAS, para orientar a comunidade na preservação e na restauração de imóveis da APA, entre outras atribuições.
} 
Em 2002, começamos a elaborar os planos urbanos, porque o plano conceitual era muito abstrato, fazia sentido para o técnico, mas para o leigo, isso era algo imperceptível [...], a gente precisava ter imagens, coisas mais concretas. Então em 2002 nós começamos a trabalhar nisso, nos projetos urbanos. Foi quando surgiram projetos mais emblemáticos Morro da Conceição, Sacadura Cabral, a requalificação da Praça Mauá, Rodrigues Alves... [...] Associado a isso teve um projeto paralelo, a cidade concebeu o "Pentágono do Milênio" - grandes obras, grandes projetos que serviriam como catalisadores de renovação. Então você tinha a Cidade da Música, a Cidade do Esporte que era o Engenhão, a Cidade das Crianças em Santa Cruz, a Cidade das Artes que era o Guggenheim e a Cidade do Samba que acabou se viabilizando [...] (informação verbal). ${ }^{8}$

Nota-se, desde esse momento, a intenção de renovar a imagem da cidade a partir da instalação de grandes equipamentos urbanos na região. Após a paralisação do projeto Porto do Rio em 2008 e o impedimento legal de construção do Museu Guggenheim Rio, a administração municipal que tomou posse em 2009, sob o comando do prefeito Eduardo Paes, apresentou nova proposta para a revitalização da Zona Portuária: o Projeto Porto Maravilha. Esse projeto toma como base as propostas do Porto do Rio, mas estabelece outros elementos importantes, tais como a definição de novos parâmetros de uso e ocupação do solo e a criação dos Certificados de Potencial Adicional de Construção (CEPACS), títulos mobiliários que permitem a construção de edifícios mais altos do que os limites atuais permitidos pela legislação. Para os nossos objetivos, é importante destacar algumas características do Porto Maravilha que foram herdadas do Porto do Rio.

Em primeiro lugar, a Zona Portuária é pensada nesses planos como vetor de crescimento da Área Central de Negócios. Vale salientar que, segundo o secretário municipal de Desenvolvimento, Felipe Góes, “[o Porto Maravilha] é um projeto absolutamente estratégico para o futuro de nossa cidade. Resgatar a região portuária é resgatar o Centro do Rio de Janeiro". ${ }^{9}$ O slogan do projeto - "uma nova cidade está nascendo" - evidencia não apenas o papel fundamental da Zona Portuária na reinvenção do imaginário a respeito da cidade, mas também o reforço dos vínculos entre a nova identidade da região e a identidade da cidade.

\footnotetext{
${ }^{8}$ Correia, Alberto. Palestra “Porto Maravilha", Instituto Pereira Passos, 21 de janeiro de 2014.

${ }^{9}$ Disponível em: <http://www.rio.ri.gov.br/web/guest/exibeconteudo?article-id=894709> Acesso em: 27 de setembro 2016.
} 
Vale ressaltar também que nos relatos de técnicos e políticos envolvidos no Porto Maravilha, o potencial econômico e cultural da região, a localização estratégica e a presença de patrimônio histórico são os motivos mais citados para justificar a intervenção. Segundo o poder público, "O Porto Maravilha é um projeto de requalificação que prevê o reencontro da Região Portuária com a cidade", pois "a degradação presenciada pelos cariocas por décadas na área será revertida em histórica onda de reformas urbanas promovidas pela Prefeitura do Rio" (RIO DE JANEIRO, 2012) ${ }^{10}$. Vale notar, portanto, a identificação entre a revitalização da região e a valorização de sua importância histórica, uma vez que a região abrange três bairros preservados pelo SAGAS (bairros Saúde, Gamboa e Santo Cristo) e, como uma das primeiras áreas ocupadas da cidade, registra considerável quantidade de imóveis tombados.

A noção de requalificação, frequentemente utilizada pelos técnicos da prefeitura, tem um caráter estratégico e está principalmente voltada para o estabelecimento de novos padrões de organização e utilização do território e para um melhor desempenho econômico. No caso do Porto Maravilha, pretende-se obter esses resultados através da sinergia entre "desenvolvimento socioeconômico" (ações econômicas comerciais, ações educacionais profissionalizantes para os moradores e comerciantes locais), "desenvolvimento imobiliário" (o estímulo aos usos habitacionais) e a "requalificação urbana" propriamente dita (CDURP, 2009). ${ }^{11}$

O ineditismo do plano é uma das características mais citadas para explicar sua eficácia. Nesse sentido, Jorge Arraes (presidente da CDURP até 2012 e atual subsecretário municipal de Projetos Estratégicos e Concessões de Serviços Públicos e Parcerias PúblicoPrivadas) identificou o Porto Maravilha como uma "grande quebra de paradigma":

[...] talvez o principal paradigma quebrado seja a mudança do eixo de desenvolvimento imobiliário para o centro da cidade. É dar, sem querer parecer uma redundância [...] mudança a visão de centro da cidade, dando uma nova centralidade urbana a esse centro. E em função disso,

\footnotetext{
${ }^{10}$ Disponível em: <http://www.portomaravilha.com.br/web/esq/imprensa/pdf/05.pdf>

${ }^{11}$ No caso, pode-se deduzir que "requalificação" compreende um processo de transformação do valor de uma região, em termos econômicos (atividades econômicas e comerciais, incorporação imobiliária), culturais (localização de usos econômicos relacionados com a cultura) e sociais (produção de espaços públicos com valor de centralidade).
} 
Entretanto, a urbanista e geógrafa Nina Rabha ${ }^{13}$, coordenadora do projeto de reestruturação da Zona Portuária à época, assinalou em entrevista cedida a diferença entre o projeto inicial do Porto do Rio e o Porto Maravilha:

O plano do Porto de 2001 foi do micro pro macro, foi de dentro pra fora, do morro pra baixada. Equacionando circulação local, aproveitando espaços vazios para implementar moradia... mantendo os índices de ocupação. Na verdade, naquele momento considerávamos que era extremamente difícil alterar isso, mas instituindo a zona mista [...] acho que na atual versão do projeto os itens estão praticamente mantidos. $O$ que está muito alterado é a intensidade e a rapidez com que a intervenção vem se colocando [...] e de alguma maneira eu temo pelos resultados que a gente possa alcançar em função dos produtos e da própria prática do Rio de Janeiro de trabalhar com macroescala. [...] quando eu olho pra o projeto de uma forma tão avassaladora, temo pela macroescala que se apresenta e pela importância estruturadora que 0 processo passa a ter pra cidade do Rio de Janeiro (RABHA, 2010).

Segundo o Estudo de Impacto de Vizinhança do Porto Maravilha (EIV), elaborado pela CDURP e pelo Instituto Pereira Passos, o objetivo do projeto é conceber um plano completo de revitalização para a área, "de forma que a transforme num novo vetor de crescimento da cidade", como ocorreu com os bairros Copacabana nos anos 1940, Ipanema e Leblon na década de 1960 e a Barra da Tijuca na década de 1970 (CDURP, 2009, p. 16). Trata-se, portanto, da tentativa de criar uma representação modelar de planejamento urbano que sirva de força motriz da nova cidade que se quer criar.

Não é por outra razão que a apresentação da exposição “Meu Porto Maravilha” (Figura 1) inicia-se com a frase "As cidades voltam-se para as suas áreas portuárias -

\footnotetext{
${ }^{12}$ ARRAES, Jorge. Seminário Patrimônio Cultural e Intervenção Urbana, 11 de setembro de 2011.

${ }^{13}$ Arquiteta com doutorado em geografia, Nina Maria Rabha foi titular da Região Administrativa da Zona Portuária entre 1993 e 2000, por indicação de Augusto Ivan Pinheiro de Freitas, na época subprefeito do Centro. Participou de diversos estudos técnicos a respeito da Zona Portuária, inclusive da pesquisa que deu origem ao projeto Porto do Rio, durante sua gestão como gerente de projetos do Instituto Pereira Passos (IPP). Com Pinheiro, escreveu o livro "Porto do Rio de Janeiro - Construindo a Modernidade", lançado em 2004. Escreveu tese de doutorado a respeito das permanências e mudanças urbanas do centro do Rio de Janeiro e artigos acadêmicos a respeito do Morro da Conceição, Rua do Lavradio e dos bairros portuários.
} 
Metrópoles do mundo inteiro têm despertado para o novo paradigma do desenvolvimento sustentável no qual a nova fronteira é a ocupação dos vazios".

Figura 1 - Exposição “Meu Porto Maravilha”

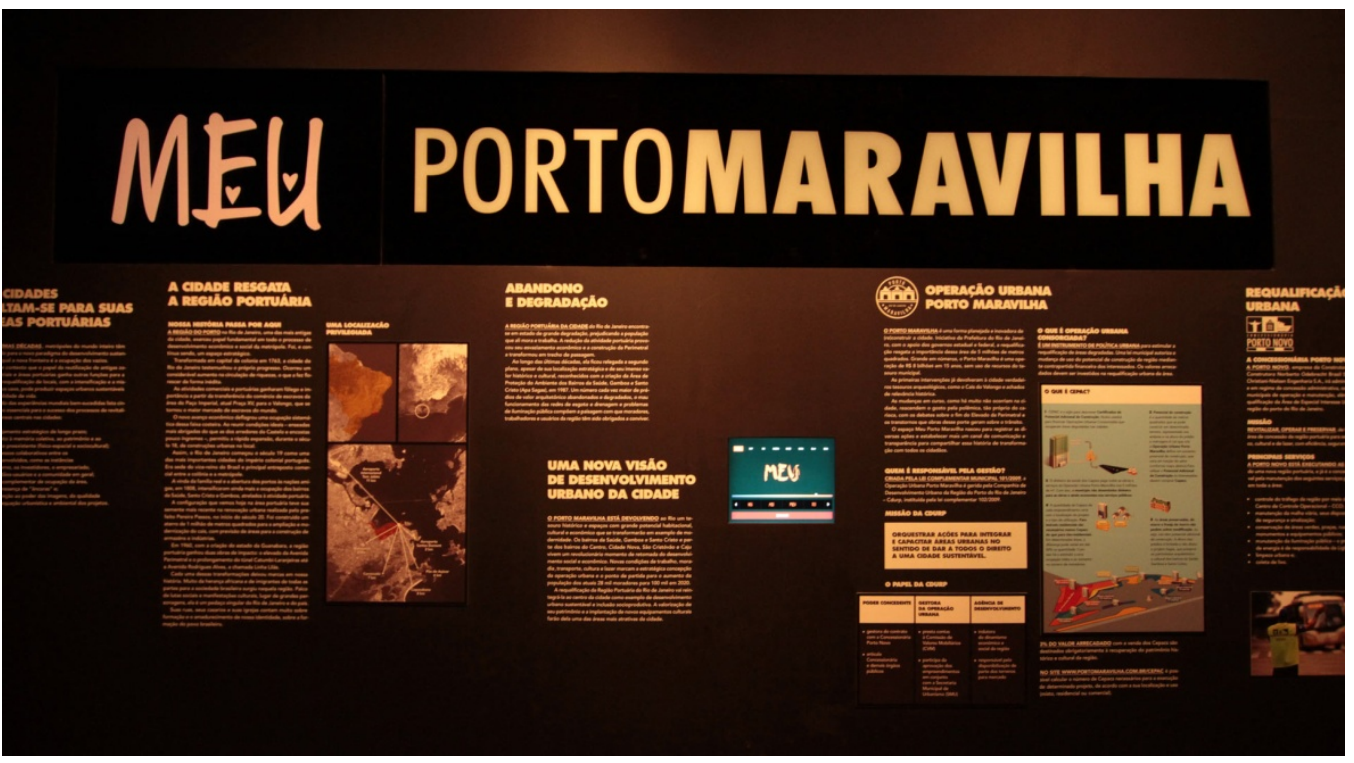

Fonte: O autor, 2012.

Os tópicos seguintes ("A cidade resgata a região portuária" e "abandono e degradação") explicitam a necessidade de se revalorizar a Zona Portuária através do resgate de sua história e vocações, além de classificar o Porto Maravilha como um modo de reverter o "isolamento" e a "deterioração" da região. O quarto tópico, "Uma nova visão de desenvolvimento urbano da cidade", enfatiza as linhas de atuação do Projeto (requalificação, desenvolvimento imobiliário e desenvolvimento socioeconômico), a criação de um novo modelo econômico da área, valorizando o "uso social turístico, cultural e de lazer, com eficiência, segurança e confiabilidade", a criação de novos prédios residenciais e o desenvolvimento socioeconômico.

Percebe-se, nesse caso, uma tentativa de construir um discurso temporal e espacial que caracteriza as propostas do projeto como inquestionáveis e cujo resultado seria a criação de um "novo" polo habitacional e cultural. Nesse sentido, saliento a pouca atenção dada às características culturais e habitacionais já existentes, e a inexistência de um "Diagnóstico Socioeconômico", como era comum, por exemplo, nos Projetos Favela Bairro e Rio Cidade. Volta-se, assim, à ideia de resgatar o Centro, refletida na intenção de 
fazer a cidade "retornar ao próprio eixo" ${ }^{14}$, às suas origens históricas, através do resgate a Zona Portuária. Ao mesmo tempo, propõe-se que a revitalização da região produzirá um efeito indutor sobre o resto da cidade, com um conjunto de edificações residenciais, comerciais e culturais. Esse "novo modelo de planejamento" pode ser entendido como a criação de um novo ethos para a cidade, englobando certa ideia de "espaço público" e “qualidade de vida”, além de determinadas percepções e usos da cidade (PIO, 2004).

\section{Espacialidade e historicidade: Alguns relatos sobre o porto}

Em nossas análises das narrativas de técnicos e políticos a respeito da Zona Portuária, foi possível perceber que o passado da região é apresentado em vários momentos como algo difuso, sem características específicas ou complexidade, e como um recurso relevante devido ao seu "potencial" econômico e cultural, mas tradicionalmente subutilizado. Em outros contextos, especialmente aqueles em que se torna necessário justificar a escolha por um tipo de intervenção, o passado da região é elaborado para demonstrar que o projeto age sobre a área apenas reforçando as vocações positivas ali já existentes, no sentido de legitimar a renovação urbana proposta através de um enquadramento da memória em que elementos específicos são estrategicamente selecionados ou descartados.

$\mathrm{Na}$ apresentação Porto Maravilha - reurbanização de desenvolvimento socioeconômico ${ }^{15}$, Jorge Arraes (presidente CDURP até 2012) associa o isolamento da área à sua degradação. Cita como fatores de degradação a baixa taxa de áreas verdes (2,5\%), a “troca de tecnologia portuária”, "pontos crônicos de alagamento" e "pontos de acúmulo de lixo"; “patrimônio arquitetônico degradado" e a "presença do elevado da Perimetral”. A vitalidade da área, muitas vezes questionada pelos planejadores, pode ser detectada durante o dia pela presença de funcionários de diversas empresas e órgãos públicos instalados na área e nos usos intensos de áreas de lazer e pequeno comércio. Essa

\footnotetext{
14 Disponível em: <http://www.portomaravilha.com.br/web/esq/imprensa/pdf/01.pdf>. Acesso em: 21 de junho de 2012.

${ }^{15}$ Disponível em: <http://portomaravilha.com.br/uploads/releases/55cb9d456026c.pdf>. Acesso em: 21 de junho de 2012.
} 
vitalidade só decai à noite, de maneira análoga ao que acontece na área central de negócios, com a vantagem de a Zona Portuária possuir um número significativo de moradores que impedem o total esvaziamento, o que não ocorre na região entre a Praça Tiradentes e a Praça XV.

Pode-se concluir que há uma tendência de os discursos oficiais representarem o projeto como a única solução possível, desconsiderando outras possibilidades urbanísticas. Esse determinismo é acompanhado por uma perspectiva essencialista que identifica a cidade como "potência" natural do país, o que naturaliza a relação entre passado e presente. Segundo a leitura de Antonio Correa, coordenador-geral do Centro de Arquitetura e Urbanismo da Secretaria Municipal de Urbanismo:

Não seria exagero afirmar que o Rio de Janeiro domina o Atlântico Sul, sendo o seu porto natural, a referência em qualquer viagem por essas águas. É nesse cenário que a Prefeitura inicia um amplo programa de intervenções urbanísticas, que alterarão significativamente a feição de boa parte do tecido urbano ainda relacionado a usos que outrora eram portuários (armazéns e galpões), possibilitando a renovação dos bairros da Saúde, da Gamboa e do Santo Cristo, extensão natural do Centro da Cidade. Vale destacar que, caso deseje, o visitante pode desembarcar e, caminhando a pé, percorrer boa parte do Centro Histórico, conhecendo exemplares da Arquitetura Barroca Brasileira, do casario eclético, do centro financeiro e comercial da cidade. Para tanto, o Rio de Janeiro busca formas de se adaptar às novas demandas, reforçando as suas naturais vocações de cidade cosmopolita e símbolo do país, com o objetivo de tornar uma experiência única a simples passagem por aqui! (CORREIA, 2010, p. 2)

Destaca-se nas representações de Sergio Dias e Antonio Correia o interesse de constituir uma nova versão da capitalidade da cidade, ou seja, a capacidade de “representar a unidade e a síntese da nação foi transformada em uma tradição única e exclusiva da cidade do Rio de Janeiro, marcando, simultaneamente, o que lhe é próprio e o que a separa das outras regiões do país" (MOTTA, 2000, p. 2). O discurso nostálgico da antiga capital, de cidade abandonada, tão comum ao discurso político da cidade até os anos 1990, dá vez ao discurso triunfante que sinaliza a construção de uma nova capitalidade. Se cada projeto de transferência de capital cria em paralelo um sentimento de frustração nas elites e na população local (VIDAL, 2011), o Porto Maravilha produz um 
discurso de renovação da imagem urbana e de criação de uma nova centralidade para a cidade, no sentido de superar simbolicamente a cidade destituída da capitalidade e o abandono da Zona Portuária.

Por fim, o plano destaca a oportunidade única de revitalizar a área, por conta do momento singular da cidade e do próprio país. Trata-se de reforçar através do uso intensivo de meios de comunicação e de promoção a ascensão econômica do Brasil e a importância do Rio de Janeiro na consolidação desse status da nação - sede da Copa do Mundo (2014) e das Olimpíadas (2016), entre outros eventos. A imagem abaixo, retirada de uma das apresentações utilizadas por políticos e técnicos do Instituto Pereira Passos (IPP), revela tanto a oportunidade econômica propiciada pelos megaeventos quanto a singularidade ou o "diferencial” da cultura carioca.

Figura 2 - Cronograma de eventos da Cidade do Rio de Janeiro



Fonte: http://portomaravilha.com.br/web/sup/OperUrbanaApresent.aspx

A linha histórica na parte superior da imagem destaca uma suposta evolução econômica e social do Brasil, enquanto as manchetes ("Brasil decola”, "O jeito do Rio", "Revivendo uma reputação") salientam o resgate da centralidade do Rio de Janeiro e a relação entre a capitalidade da cidade e a identidade nacional. Caracteriza-se, portanto, o que Amanda Wanis (2011) chamou de "Momento-Rio", que remete à consciência do 
momento especial de retomada da importância da cidade e de superação da crise da cidade. Na apresentação “Porto Maravilha: Desafios e oportunidades"”, Jorge Arraes enfatizou a singularidade cultural da cidade e sua visibilidade atual. Tais características, tidas como "naturais", evocam por um lado metáforas poderosas a respeito do papel do Rio de Janeiro como "caixa de ressonância" do Brasil, ao mesmo tempo em que se tenta destacar a oportunidade imperdível para a cidade alcançar definitivamente o status de cidade global. Tal discurso evidencia um ambiente de disputa externa entre cidades ou regiões, o que levaria as administrações locais a criarem ambientes atrativos, considerando as frequentes mudanças do mercado externo (SANCHEZ, 2001).

Nesse processo, torna-se imprescindível agir seletivamente sobre as narrativas históricas da região e adaptá-las ao imaginário da cidade global e cosmopolita. Por outro lado, uma análise mais atenta revela a existência de disputas internas pela definição dos significados da área e por reconhecimento e afirmação identitária por parte de grupos locais. No intuito de produzir uma imagem harmônica e triunfante da região, essas disputas são frequentemente omitidas pelo planejamento proposto oficialmente.

\section{Considerações finais}

A prefeitura da cidade, através da intervenção urbana do Porto Maravilha, constitui um discurso de regeneração do porto do Rio de Janeiro como condição decisiva do resgate da cidade. Esse discurso agiria legitimando a desatenção da municipalidade carioca para com a história de usos desse espaço pela população da região, elementos constituintes de sua historicidade e espacialidade. Nos discursos da prefeitura que analisamos, o porto dificilmente aparece como sujeito, como um lugar que porta uma tradição ${ }^{17}$, mas antes figura como um objeto a sofrer intervenção do poder público, visto ser reputado como decadente e demandante de "regeneração" por uma reforma urbana. As obras do Porto Maravilha também atendem a uma perspectiva de integração do Rio de Janeiro em uma rede internacional de cidades globais, que significa sinalizar, em

\footnotetext{
${ }^{16}$ ARRAES, Jorge. Porto Maravilha: Desafios e oportunidades. Auditório Caixa, 13 de dezembro de 2011.

${ }^{17} \mathrm{O}$ conceito de tradição que aqui utilizamos é de Gadamer, e designa a constituição intrínseca dos costumes de um povo. Cf. GADAMER, Hans G. Verdade e Método. Petrópolis: Vozes, 1997. p. 476.
} 
âmbito internacional, que o Rio de Janeiro é um espaço legitimado como uma urbe que atende a padrões globais de exigência para investimentos, turismo e realização de grandes eventos. Há, portanto, na ação da prefeitura sobre o porto, uma perspectiva de sobrepujar a historicidade e a espacialidade dessa região, em nome de uma reformulação daquele espaço, a fim de que ela possa legitimar a cidade no plano das demandas econômicas internacionais. Nesse contexto, os discursos da municipalidade sobre o patrimônio histórico do porto aparecem mais apontando para ele como um elemento alegórico sobre o pitoresco desse espaço, propiciando somar para torná-lo mais atraente à visitação. Com essa conduta a prefeitura lança a história dessa zona da cidade no plano da superfície, vazia de profundidade histórica. Ao assim proceder, coloca em primeiro plano uma razão econômica que não reconhece a singularidade da constituição toda própria de cada espaço, e abre mão das possibilidades de se lançar um diálogo entre as demandas econômicas do mundo contemporâneo e as demandas locais dos habitantes da região e a tradição que ela porta.

Para "regenerar" a cidade através de sua intervenção portuária com vistas ao Jogos Olímpicos de 2016, a prefeitura do Rio de Janeiro aponta para mais além de uma aniquilação do passado, como fora a perspectiva dominante na reforma portuária de Rodrigues Alves realizada entre 1903 e 1906 (AZEVEDO, 2003, p. 38). Isso foi feito de forma a acrescentar um novo elemento à tradição secular que a cidade apresenta de valorização da ideia de progresso (FREYRE, 1959). Podemos dizer que o projeto Porto Maravilha visa fazer uso do passado submetendo-o aos seus horizontes de expectativas que vinculam o futuro da cidade às demandas de uma economia global. Assim, os elementos simbólicos que remetem a um tempo pretérito tornam-se alegorias que colocam a história de uma região em uma instância de superfície. O passado vazio de profundidade histórica é colocado a serviço de um futuro pretensamente triunfante do que seria um novo Rio de Janeiro, cidade sede de megaeventos, como as Olimpíadas de 2016. 


\section{Referências}

ARRAES, Jorge. Porto Maravilha: desafios e oportunidades. Rio de Janeiro, 2011. Palestra realizada no auditório Caixa, 13 de dezembro de 2011.

ARRAES, Jorge. Patrimônio cultural intervenção urbana. Rio de Janeiro, 2011. Palestra realizada no Instituto dos Aruiteteos do Brasil, 11 de setembro de 2011

AZEVEDO, André Nunes. de. A reforma Pereira Passos: uma tentativa de integração urbana. Inserir título da revista. Rio de Janeiro: UERJ/LPP/Fórum-Rio. n. 10, maio/ago. p. $35-64,2003$.

BOXER, Charles. Salvador Correia de Sá e a luta pelo Brasil e Angola. Rio de Janeiro: Brasiliana, 2010.

CANABRAVA, Alice Piffer. 0 comércio português no Rio da Prata (1580-1640). Belo Horizonte: Itatiaia; São Paulo: Edusp, 2010.

CARVALHO, Lia Aquino de. Habitações populares. Rio de Janeiro: Secretaria Municipal de Cultura, 1995.

CDURP. Estudo de impacto de vizinhança: operação urbana consorciada da Região do Porto do Rio, 2009. Disponível em: <http://www.portomaravilha.com.br/eiv/>. Acesso em: 23 jan. 2011.

CORREIA, Alberto. Palestra "Porto Maravilha”. Rio de Janeiro, 2014. Palestra realizada no Instituto Pereira Passos, 21 de janeiro de 2014

CORREIA, Antônio. Rio de Janeiro: Cidade do Atlântico Sul. Revista Porto Maravilha, n. 1, março, 2010.

DIAS, Sérgio. Rio de Janeiro: Porto Maravilha. In: ANDREATTA, Verena (Org.) Porto Maravilha e o Rio de Janeiro + 6 casos de sucesso de revitalização portuária. Rio de Janeiro: Casa da Palavra, 2011.

FERRARA, Lucrécia D’Aléssio. Ver a cidade. São Paulo: Nobel, 1982.

FRAGOSO, João Luis; FLORENTINO, Manolo. O arcaísmo como projeto. Rio de Janeiro: Hucitec, 1993.

FREYRE, Gilberto. Ordem e progresso. Rio de Janeiro: José Olímpio, 1959. 
GADAMER, Hans G. Verdade e método. Petrópolis: Vozes, 1997.

GADAMER, Hans G.; FROUCHON, Pierre (Orgs.). O problema da consciência histórica. Rio de Janeiro: Ed FGV, 1998.

HOLZER, Werther. O conceito de lugar na geografia cultural humanista: uma contribuição para a geografia contemporânea. Niterói: GEOgraphia. Revista do Programa de Pósgraduação em geografia da UFF. v. 5, n.10, p. 113-123, 2003.

INSTITUTO BRASILEIRO DE GEOGRAFIA E ESTATÍ́STICA. Censos demográficos de 1872, 1890 e 1900. Rio de Janeiro: IBGE, 2010. Disponível em:

http://www.cens02010.ibge.gov.br/sinopse/index.php?dados=6\&uf=00. Acesso em: $15 / 04 / 2016$.

LAMARÃO, Sérgio Tadeu de Niemeyer. Dos trapiches ao porto. Rio de Janeiro: Secretaria Municipal de Cultura, 1991.

MOTTA, Marly Silva da. O Rio de Janeiro continua sendo? Rio de Janeiro: CPDOC, 2000.

PIO, Leopoldo Guilherme. Preservando o presente: novos usos e sentidos do patrimônio no projeto Porto Maravilha. 2014. Tese (Doutorado em Ciências Sociais) - UERJ, Programa de Pósgraduação em Ciências Sociais, Rio de Janeiro, 2014.

RABHA, Nina Maria de Carvalho Elias. Bairros Portuários: aspectos sociais e culturais. In: SCHWEISER, Peter; CESARIO, Sebastiana (Orgs.). Revitalização de centros urbanos em áreas portuárias. Rio de Janeiro: Viveiros de Castro, 2004.

RABHA, Nina Maria de Carvalho Elias. Entrevista concedida a Leopoldo Guilherme Pio. Rio de Janeiro, 20 fev, 2010.

RIO DE JANEIRO. Prefeitura do Rio de Janeiro. Plano estratégico da Prefeitura do Rio de Janeiro (2013-2016): uma cidade mais integrada e competitiva. Rio de Janeiro, 2013.

RIO DE JANEIRO. Prefeitura. Preservar a memória de uma cidade moderna. Rio de Janeiro, 2014. Disponível em: <http://wwwo.rio.rj.gov.br/patrimonio/apac.shtm>. Acesso em: 12 de março de 2014 .

RIO DE JANEIRO. Prefeitura. Termo de referência. Objeto: gestão do equipamento denominado "Museu de Arte do Rio", Rio de Janeiro, 2011. Mimeo.

RIO DE JANEIRO. Secretaria Municipal de Urbanismo. Porto do Rio: plano de Recuperação e revitalização da Região Portuária do Rio de Janeiro. Rio de Janeiro, 2001. 
RODRIGUES, Antônio Edmilson Martins. Em algum lugar do passado. Cultura e história na cidade do Rio de Janeiro. In: AZEVEDO, André Nunes. de. Rio de Janeiro: capital e capitalidade. Rio de Janeiro: Depext/UERJ, 2002.

SANCHEZ, Fernanda. A reinvenção das cidades na virada de século: agentes, estratégias e escalas de ação política. Revista de Sociologia Política, Curitiba, n. 16, jun., 2001.

SENNETT, Richard. Carne e pedra: o corpo e a cidade na civilização ocidental. Rio de Janeiro: Record, 1994.

SEVCENKO, Nicolau. A literatura como missão: tensões sociais e criação cultural na Primeira República. São Paulo: Cia. das Letras, 2003.

TUAN, Y Fu. Topofilia, um estudo da percepção, atitudes e valores do meio ambiente. São Paulo: Difel, 1980.

VIDAL, Laurent. Capitais sonhadas, capitais abandonadas Considerações sobre a mobilidade das capitais nas Américas (séculos XVIII - XX). História, v.30, n.1, jan./jun., 2011.

WANIS, Amanda. Cidades criativas: a construção de um ideário e sua influência na cidade do Rio de Janeiro.2011. Dissertação (Mestrado em Arquitetura e Urbanismo) Universidade Federal Fluminense, Programa de Pós-graduação em Arquitetura e Urbanismo, 2011. 